\title{
Research Paper: Comprehensive Assessment and Zonation of Drought Risk and Vulnerability in Kerman Province
}

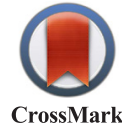

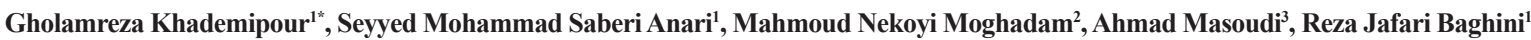

1. Disaster and Emergency Management Center, Kerman University of Medical Sciences, Kerman, Iran

2. Department of Health Management, Faculty of Management and Information Sciences, Kerman University of Medical Sciences, Kerman, Iran.

3. Kerman Agriculture Jihad Organization, Kerman, Iran.

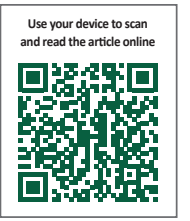

Ctration: Khademipour Gh, Saberi Anari SM, Nekoyi Moghadam M, Masoudi A, Jafari Baghini R. Comprehensive Assessment and Zonation of Drought Risk and Vulnerability in Kerman Province. Health in Emergencies and Disasters Quarterly. 2018; 3(2):113-119. https://doi.org/10.29252/NRIP.HDQ.3.2.113

https://doi.org/10.29252/NRIP.HDQ.3.2.113

Article info:

Received: 04 May 2017

Accepted: 01 Oct. 2017

\section{Keywords:}

Vulnerability, Drought assessment, Kerman

\begin{abstract}
Background: Drought can be considered as a characteristic deviation from the normal climatic conditions that manifest itself in variables like rainfall, soil moisture and level of water rivers and underground water. According to the National Drought Monitoring and Warning Center of Iran and based on the SPI index, by February 2017, around $60 \%$ of Kerman Province was involved in severe drought, and about $16 \%$ suffered from severe drought. The risk of drought is a function of the intensity and duration of drought as well as the vulnerability of the community against the drought. This study aims to comprehensively evaluate the risk of drought and its mapping in Kerman Province.
\end{abstract}

Materials and Methods: This is a qualitative study that besides determining the risk of drought, assess the level of vulnerability of Kerman Province against drought. In order to evaluate the risk of drought, we used the equation DRI=DHI * DVI. Using the relationship DHI $=(\mathrm{MDr} * \mathrm{MDw})+(\mathrm{VSDr}$ * VSDw $)+(\mathrm{SDr} * \mathrm{SDw})$, the Drought Hazard Index was extracted. The data obtained from the study was mapped by using ArcGIS 9.0.

Results: Based on the study results, $6.3 \%$ of Kerman Province, $11581 \mathrm{Km}^{2}$, was involved in severe drought. This province with mean drought vulnerability index of 4.5 , has low tolerance against drought and the consequences could affect dramatically the communities in this province.

Conclusion: The measures to reduce the vulnerability in social, economic, ecologic, and health areas not only lower the risk in the drought-affected areas, but also prevent secondary damages like immigration, marginalization, and social, cultural problems in large and capital cities of the province.

\section{Introduction}

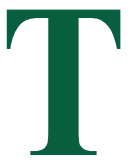

he impacts of climate change on human health are well known to mankind. Increased knowledge on the trends of climate change has led health researchers to consider assessing the potential mechanisms of climate change and its impacts on human health [1] (Figure 1). A change in climate affects precipitation, temperature, and evapotranspiration potential, ultimately affecting the severity of drought [2]. Drought is a long-lasting regional event occurring mainly due to low precipitation and high rates of evaporation. It can be considered as a characteristic of deviation from normal weather conditions reflected on variables such as precipitation, soil moisture, surface of rivers, and water

\section{* Corresponding Author:}

Gholamreza Khademipour, MSc.

Address: Disaster and Emergency Management Center, Kerman University of Medical Sciences, Kerman, Iran.

E-mail: khadem115@yahoo.com 


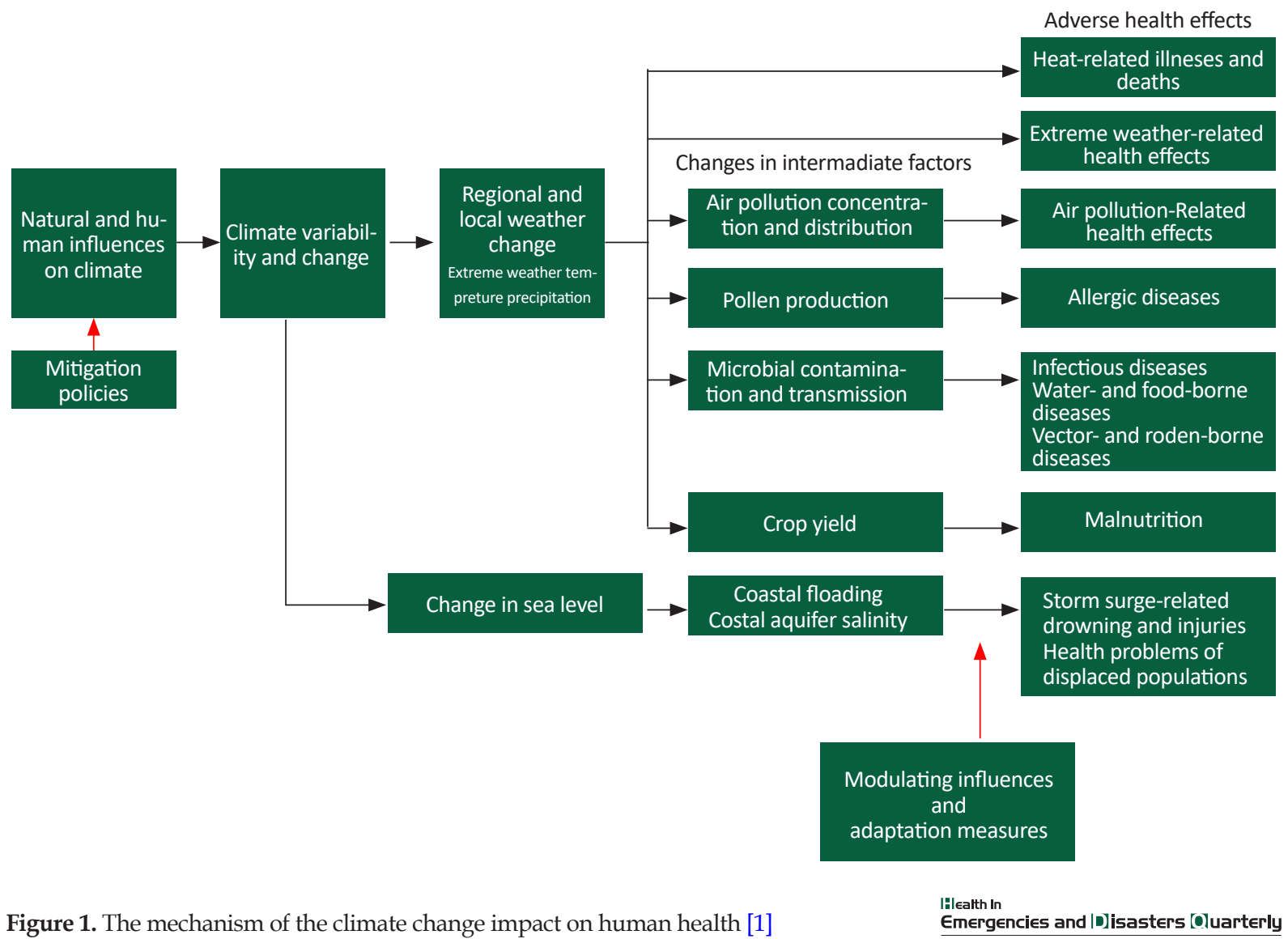

table. In fact, drought is a phenomenon in a certain period and location that is significantly different from one region to another [3]. According to the National Drought Warning and Monitoring Center and based on the Standardized Precipitation Index (SPI) index, about 74 percent of Iran's area was affected by drought in the year ending in late January 2017 (Figure 2). The same report also showed that more than $98 \%$ of Kerman province was affected by mild to extreme drought during the mentioned period. About $60 \%$ of the province's area was affected by severe drought and about $16 \%$ suffered from extreme drought ${ }^{1}$. Natural disasters, including drought, have a variety of effects on the environment and human health. Some of these effects, such as the reduction of food supplies and the loss of human habitats, appear in short-term and others, such as mortality and physical damages, in the long-term [4]. Observations and short-term studies of climate change suggest that even minor changes in temperature and precipitation in a region can affect diseases like malaria, diarrhea and malnutrition. Drought may have a wide impact on human health. In addition to the nutritional status of people, it might have a profound effect on the spread of infectious diseases, the occurrence of fires in forests and pastures, and air pollution, especial-

1. http://ndwmc.irimo.ir/far/ ly in developing and low-income countries [5]. Drought is a long dry period in the climate cycle that often leads to displacement of population, water and food shortages, adverse environmental effects, and negative impacts on the community health. The occurrence of drought periods in all climate systems is common and predictable.

The World Health Organization (WHO) introduced the following factors as the main causes of vulnerability to drought: demographic pressures on the environment, food insecurity, severe economic dependence on agriculture, poor infrastructure (traditional irrigation systems, lack of wastewater treatment and inadequate water supply), weak health system of the region, lack of drought warning and monitoring systems, population displacement, and the occurrence of inappropriate socioeconomic conditions (economic crises, political instability and armed conflicts) [6]. The risk of drought is, in fact, the probability of drought-causing consequences for health, economy and environment. Drought risk is a function of the severity and duration of the drought, as well as the degree of community vulnerability to drought [7]. The Kerman province has a population of over 3 million people in an area of more than 1800 thousand square kilometers. It is located in the southeast of Iran's plateau between 54 degrees 21 


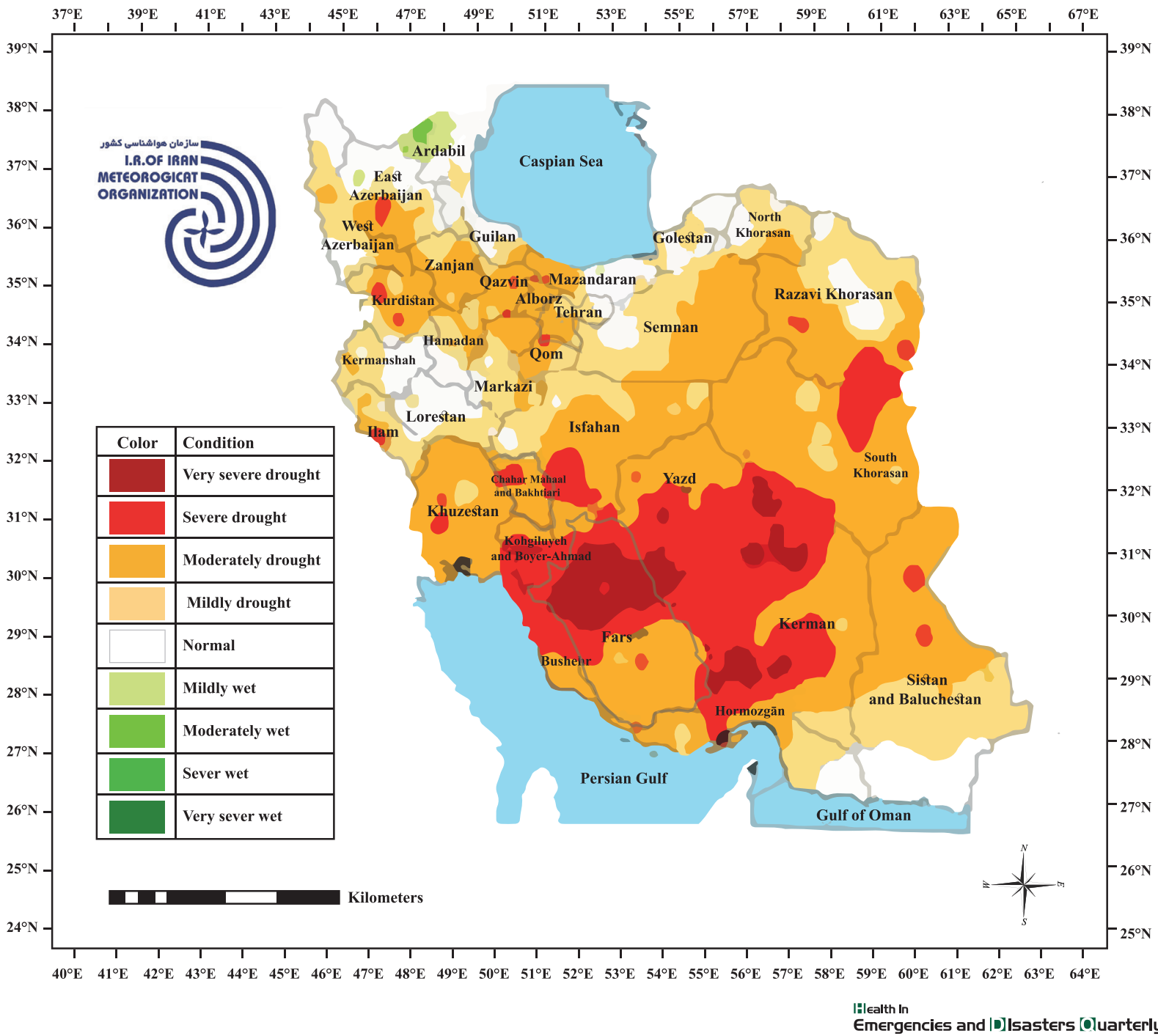

Figure 2. Drought in Iran during the one-year period till 2017/01/19 [12]

minutes and 59 degrees 34 minutes of east longitude and 26 degrees 29 minutes to 31 degrees 58 minutes of north latitude. This province comprises 23 cities and accounts for $11.15 \%$ of the country's territory as the vastest province of Iran [8]. The objective of this study is to perform a comprehensive assessment and zonation of drought risk and vulnerability in Kerman province. The present study will help to identify the risks of drought and its social and health consequences, and explain the vulnerability of the human communities living in the province against the phenomenon and its consequences.

\section{Materials and Methods}

The present research is a quantitative and qualitative study that determines the drought risk and vulnerability of Kerman province. In order to evaluate the drought risk, the following equation was used [9]:

\section{$D R I=D H I \times D V I$}

, where DRI is the Drought Risk Index, DHI is the Drought Hazard Index, and DVI is Drought Vulnerability Index. Given that the Standardized PrecipitationEvapotranspiration Index (SPEI) is an approved and suitable tool for monitoring drought events, it was used to calculate DHI. At first, the drought severity of the cities in Kerman province was calculated using the data from the precipitation stations based on the SPEI for a one-year period ending April 2017. Then, according to the SPI algorithm shown in Tables 1 and 2, drought severity was determined at 4 (mild, moderate, severe and extreme) levels [10]. The Drought Hazard Index was extracted by assigning weight to drought severity levels using the following relation:

$$
D H I=(S D r \times S D w)+(V S D r \times V S D w)+(M D w \times M D r)
$$


Table 1. Drought severity classification based on SPEI

\begin{tabular}{cc}
\hline Drought Severity & SPEI \\
\hline Mild drought & $0-0.99$ \\
Moderate drought & $1-1.49$ \\
Severe drought & $5.1-1.99$ \\
Extreme drought & $2 \leq$ \\
\hline & Illealth in \\
\hline
\end{tabular}

, where MDr denotes the Moderate Drought Coefficient, MDw denotes Moderate Drought Weight, SDr denotes Severe Drought Coefficient, and SDw indicates Severe Drought Weight. Also, VSDr and VSDw are extreme drought coefficient and weight, respectively. According to the background and general approach of the study, the vulnerability indicators were determined and analyzed based on the indicators proposed by the WHO and the United Nations Development Program (UNDP) [11]. In this study, measurable indicators were used to assess the drought vulnerability. In general, DVI was studied in four groups of economic, social, health and ecological indicators (Table 3).

Based on the impact and importance of DVI, the weight and coefficient for each indicator were determined with the help of experts and qualified individuals. The general index was calculated based on the types of vulnerability. Finally, the DVI was extracted for the cities of Kerman province using the following equation:

$$
D V I=\frac{\begin{array}{c}
\text { Total Ecological Index }+ \text { Total Health Indicator }+ \text { Total } \\
\text { Economic Indicator }+ \text { Total Social Indicator }
\end{array}}{\text { Total number of indicators }}
$$

The zonation of research data was performed using ArcGIS 9.0 software. The resulting maps show the drought risk and vulnerability based on a 4-level scale (low, moderate, high, very high) in Kerman province.

\section{Results}

\begin{tabular}{|c|c|c|c|}
\hline Severity of Drought & Weight & Percentage of Drought & Coefficient \\
\hline \multirow{5}{*}{ Moderate } & \multirow{5}{*}{1} & 9 & 1 \\
\hline & & $9.1-10$ & 2 \\
\hline & & & \\
\hline & & $10.1-11$ & 3 \\
\hline & & 11 & 4 \\
\hline \multirow{5}{*}{ Severe } & \multirow{5}{*}{2} & 3.5 & 1 \\
\hline & & $3.6-4.5$ & 2 \\
\hline & & & \\
\hline & & $4.6-5.5$ & 3 \\
\hline & & 5.6 & 4 \\
\hline \multirow{5}{*}{ Extreme } & \multirow{5}{*}{3} & 1.5 & 1 \\
\hline & & $1.6-2$ & 2 \\
\hline & & & \\
\hline & & $2.1-2.5$ & 3 \\
\hline & & 2.6 & 4 \\
\hline
\end{tabular}

Table 2. Drought weight and coefficients based on severity and percentage 
Table 3. Drought vulnerability indicators

\begin{tabular}{|c|c|c|c|}
\hline Type of Vulnerability & Weight & Vulnerability Index & Vulnerability Coefficient \\
\hline \multirow{5}{*}{ Social } & \multirow{5}{*}{1} & Population density & Low (1), Medium (2), High (3), Very High(4) \\
\hline & & Women to men ratio & Low (1), Medium (2), High (3), Very High (4) \\
\hline & & Unemployment rate & Low (1), Medium (2), High (3), Very High (4) \\
\hline & & Illiteracy rate & Low (1), Medium (2), High (3), Very High (4) \\
\hline & & $\begin{array}{l}\text { The ratio of the rural population to the } \\
\text { urban population }\end{array}$ & Low (1), Medium (2), High (3), Very High (4) \\
\hline \multirow{3}{*}{ Economic } & \multirow{3}{*}{2} & Poverty & Low (1), Medium (2), High (3), Very High (4) \\
\hline & & Employment rate in agricultural sector & Low (1), Medium (2), High (3), Very High (4) \\
\hline & & Annual production of agricultural products & Low (1), Medium (2), High (3), Very High (4) \\
\hline \multirow{5}{*}{ Health } & \multirow{5}{*}{3} & Access to healthcare services & Low (1), Medium (2), High (3), Very High (4) \\
\hline & & Coverage of health insurance & Low(4), Medium(3), High(2), Very High (1) \\
\hline & & & \\
\hline & & Access to safe and healthy water & Low(4), Medium(3), High(2), Very High (2) \\
\hline & & Access to sewage disposal system & Low(4), Medium(3), High(2), Very High (2) \\
\hline \multirow{4}{*}{ Ecological } & \multirow{4}{*}{4} & Percentage of cultivated land and gardens & Low (1), Medium (2), High (3), Very High (4) \\
\hline & & Waste wasted & Low (1), Medium (2), High (3), Very High (4) \\
\hline & & $\begin{array}{l}\text { Agricultural lands under traditional irriga- } \\
\text { tion }\end{array}$ & Low (1), Medium (2), High (3), Very High (4) \\
\hline & & Annual water consumption & Low (1), Medium (2), High (3), Very High (4) \\
\hline
\end{tabular}

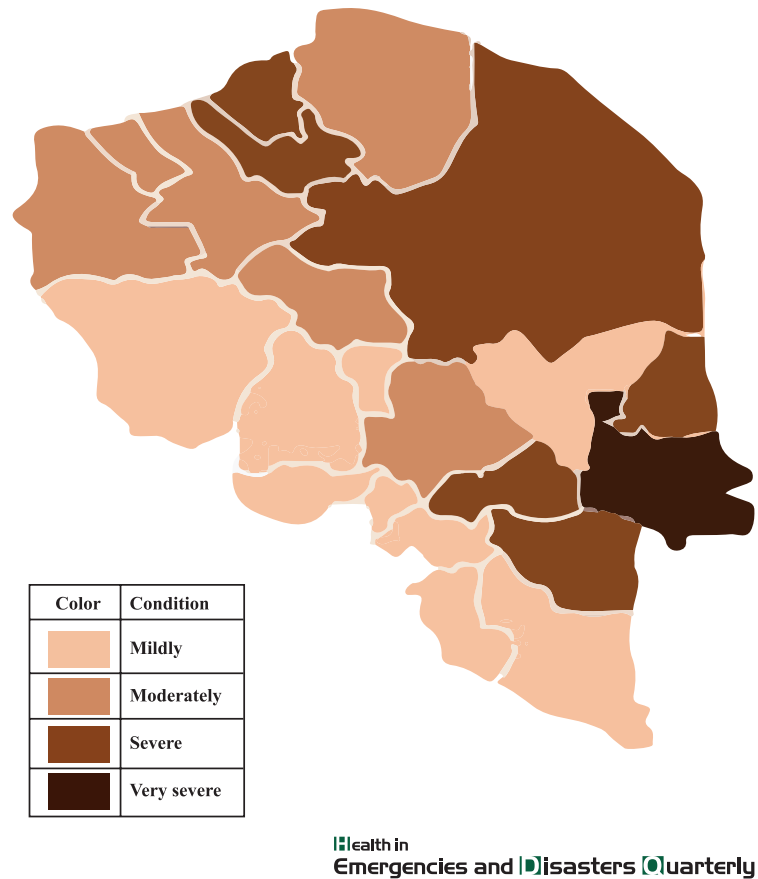

Figure 3. Drought hazard zonation of Kerman province

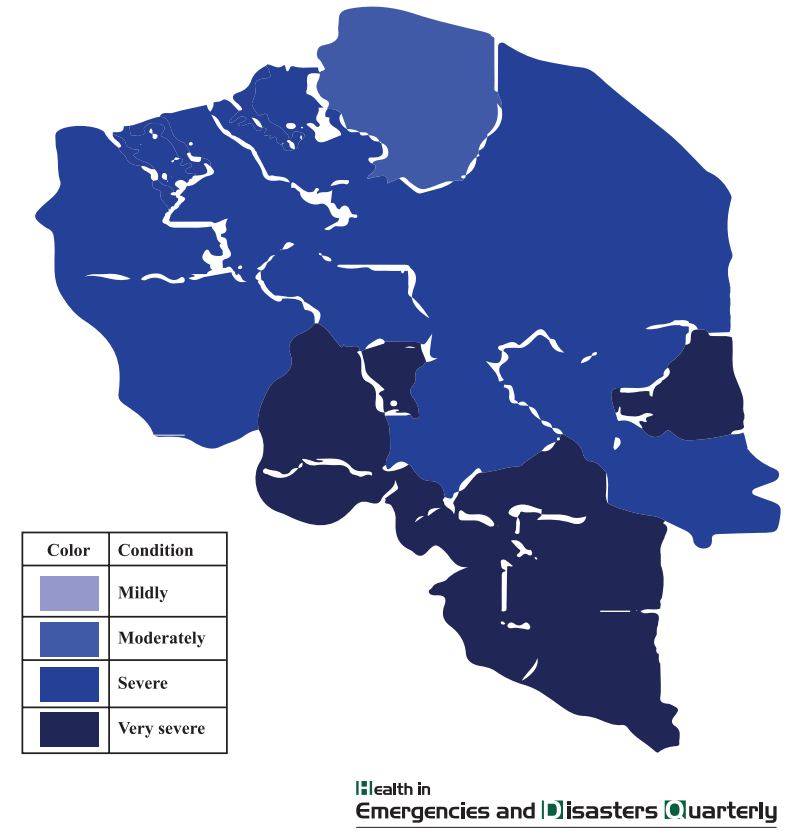

Figure 4. Drought vulnerability zonation of Kerman province 
Table 4. Evaluation results of drought vulnerability indicators

\begin{tabular}{|c|c|c|c|c|c|c|c|}
\hline City & $\begin{array}{l}\text { Social Vul- } \\
\text { nerability }\end{array}$ & $\begin{array}{c}\text { Economic } \\
\text { Vulnerability }\end{array}$ & $\begin{array}{l}\text { Health Vul- } \\
\text { nerability }\end{array}$ & $\begin{array}{c}\text { Ecological } \\
\text { Vulnerability }\end{array}$ & $\begin{array}{l}\text { Total Vulner- } \\
\text { ability }\end{array}$ & DVI & DVI Level \\
\hline Arzooyie & 19 & 6 & 4 & 7 & 71 & 46.5 & Very high \\
\hline Anar & 11 & 3 & 3 & 5 & 49 & 76.3 & High \\
\hline Baft & 17 & 5 & 2 & 7 & 61 & 4.7 & Very high \\
\hline Bardsir & 12 & 4 & 2 & 7 & 54 & 1.4 & High \\
\hline Bam & 15 & 4 & 3 & 6 & 56 & 3.4 & High \\
\hline Jiroft & 15 & 3 & 2 & 7 & 55 & 2.4 & High \\
\hline Rabar & 18 & 4 & 5 & 5 & 61 & 7.4 & Very high \\
\hline Ravor & 15 & 2 & 2 & 3 & 37 & 8.2 & Moderate \\
\hline Rafsanjan & 13 & 3 & 2 & 4 & 41 & 1.3 & High \\
\hline Roodbar & 19 & 3 & 8 & 7 & 77 & 9.5 & Very high \\
\hline Reygan & 19 & 2 & 6 & 4 & 57 & 4.4 & High \\
\hline Zarand & 13 & 4 & 2 & 5 & 47 & 6.3 & High \\
\hline Sirjan & 8 & 4 & 2 & 6 & 46 & 5.3 & High \\
\hline Shahr-e-babak & 12 & 2 & 3 & 4 & 41 & 1.3 & High \\
\hline Anbar Abad & 16 & 5 & 4 & 7 & 66 & 1.5 & Very high \\
\hline Faryab & 17 & 3 & 6 & 9 & 77 & 9.5 & Very high \\
\hline Fahraj & 19 & 2 & 7 & 4 & 60 & 6.4 & Very high \\
\hline Qale Ganj & 21 & 4 & 6 & 7 & 75 & 7.5 & Very high \\
\hline Kerman & 9 & 3 & 2 & 7 & 49 & 7.3 & High \\
\hline Kohbanan & 15 & 2 & 4 & 3 & 43 & 3.3 & High \\
\hline Kahnouj & 16 & 7 & 4 & 8 & 74 & 7.5 & Very high \\
\hline Manuajan & 18 & 3 & 5 & 7 & 67 & 1.5 & Very high \\
\hline Normashir & 19 & 2 & 5 & 6 & 62 & 7.4 & Very high \\
\hline
\end{tabular}

The study results indicate that the mean DVI in Kerman province is 4.5 (high vulnerability). The analysis of the provincial vulnerability index showed that $98 \%$ of the cities of Kerman province are at severe and extreme drought (Table 4). According to the results of this study, 6.3 percent of the area of the Kerman province (11581 square kilometers) is at a high drought risk. Of the 23 cities of Kerman province, 6 cities are at a high drought risk, which is a total of $36.3 \%$ of the province. The cities of Shahr-e-Babak, Ravar, Rafsanjan, Jiroft, Bardsir, and
Anar have a moderate drought risk. A total of 39.1\% cities of Kerman province are at a low drought risk. Based on the maps of drought risk analysis, the least drought risk is related to southern and central cities. Thus, the cities of Kahnouj, Manojan, Arzooyie, Faryab, and Baft have the lowest drought risk. Kerman, as the largest and most populated city, is at very high drought risk. In other words, about one-third of the total population of the province living in this city faces a high risk of drought. The ecological and social factors were found to have the 
highest impact on drought vulnerability in the studied population. Figures 3 and 4 show the zonation of drought vulnerability and risk in Kerman province by cities.

\section{Discussion}

The present study shows that Kerman province has high drought vulnerability in general. The mean vulnerability index of 4.5 shows a low degree of drought resiliency in Kerman, where the consequences can affect the communities profoundly and extensively. Based on the study of Shahid and Behroan (2008), 20.6 percent of the western parts of Bangladesh are at a very high drought risk, and 12.7 percent have a high drought risk. According to this study, $25 \%$ of the western parts of Bangladesh are at a low drought risk, which shows a greater risk and vulnerability than Kerman province [9].The low drought hazard index has mitigated the drought risk in some of the cities of Kerman province. However, the vulnerability index in these cities, as in other cities of the province, is inadequate. The major result of this study is the direct correlation of developmental indicators with vulnerability and its role in drought risk, which is consistent with the study of Hayes (2006) on drought assessment indicators [11]. So, the better social and economic development of the communities, the less they are vulnerable to drought and are more resistant to secondary drought effects.

\section{Conclusion}

Considering that some of the factors affecting drought severity and hazard index, such as precipitation and temperature variations, are not capable of short-term local control and correction, it is essential for the community and authorities to focus on the vulnerability components. Components such as population density, annual water consumption, water wasted, cultivated area, livelihood status and poverty level can be improved by proper and appropriate planning. Despite the high drought hazard risk and severity, it can reduce the risk greatly and increase social resiliency against drought. It is recommended that provincial planners and authorities while trying to reduce drought severity and optimize water management in the province should focus their programs on improving the drought components and preventing the emergence of some drought-related adverse effects. The vulnerability mitigation measures in the social, economic, ecological and health areas can reduce the drought risk and its secondary damages such as migration, marginalization, social and cultural problems in the major cities. It is recommended that social scientists and drought researchers, based on this study, should identify and investigate the ways of empowering and increasing the resilience to the drought phenomenon.

\section{Acknowledgements}

This research did not receive any specific grant from funding agencies in the public, commercial, or not-forprofit sectors.

\section{Conflict of Interest}

The authors declared no conflicts of interest.

\section{References}

[1] Haines A. Health effects of climate change. JAMA. 2004 Jan 7; 291(1):99. doi: 10.1001/jama.291.1.99

[2] van Lanen HA, Tallaksen L, Rees G. Droughts and climate change. Brussels: Commission of the European Communities; 2007.

[3] Tallaksen LM, Van Lanen HA. Hydrological drought: Processes and estimation methods for streamflow and groundwater. Amsterdam: Elsevier; 2004

[4] Duclos P, Vidonne O, Beuf P, Perray P, Stoebner A. Flash flood disaster-nîmes, France, 1988. European Journal of Epidemiology. 1991; 7(4):365-71. doi: 10.1007/bf00145001

[5] Bouma MJ, Kovats RS, Goubet SA, Cox JS, Haines A. Global assessment of El Niño's disaster burden. The Lancet. 1997; 350(9089):1435-8. doi: 10.1016/s0140-6736(97)04509-1

[6] World Health Organization. The management of nutrition in major emergencies. Geneva: World Health Organization; 2000.

[7] Iglesias A, Cancelliere A, Wilhite DA, Garrote L, Cubillo F. Coping with drought risk in agriculture and water supply systems. Springer Netherlands; 2009; doi: 10.1007/978-14020-9045-5

[8] Shahid S, Behrawan H. Drought risk assessment in the western part of Bangladesh. Natural Hazards. 2008; 46(3):391-413. Doi: 10.1007/s11069-007-9191-5

[9] Guttman NB. Accepting the standardized precipitation index: A calculation algorithm. JAWRA Journal of the American Water Resources Association. 1999; 35(2):311-22. doi: 10.1111/j.1752-1688.1999.tb03592.x

[10] Hayes MJ. Drought indices. New Jersey: John Wiley \& Sons, Inc.; 2006.

[11] Ghazanfar Pour H, Kamandari M, Mohammadi Soleimani M. [A study of the impact of geographical factors on the pattern of rural housing via, in kerman province (Persian)]. Quarterly Geographical Journal of Chashmandaz-E-Zagros. 2014; 5(18):125-42. 